\title{
Fragilidade da rede social de famílias de crianças com doença crônica
}

\author{
Fragility of the social network of families of children with chronic disease \\ Fragilidad de la red social de familias de niños con enfermedad crónica
}

\author{
Yana Balduíno Araújo', Altamira Pereira da Silva Reichert', \\ Maria Gorete Lucena de Vasconcelos", Neusa Collet ${ }^{1}$ \\ ' Universidade Federal da Paraíba, Centro de Ciências da Saúde, \\ Programa de Pós-Graduação em Enfermagem. João Pessoa-PB, Brasil.
} "Universidade Federal de Pernambuco, Centro de Ciências da Saúde, Departamento de Enfermagem. Recife-PE, Brasil.

Submissão: 25-06-2012 Aprovação: 19-09-2013

\section{RESUMO}

A doença crônica na infância afeta as relações sociais familiares. A rede social pode contribuir para um melhor enfrentamento ao fornecer apoio. Objetivou-se analisar as fragilidades da rede social de famílias de crianças com doença crônica. Trata-se de uma pesquisa qualitativa, realizada em um hospital público da Paraíba entre abril e junho de 2011, utilizando genograma, ecomapa e entrevista semiestruturada com sete familiares de crianças com doença crônica. A análise temática dos resultados possibilitou caracterizar a rede e apreender as interações sociais na trajetória da doença e os tipos de apoio recebidos. A categoria empírica (des)articulação da rede social de famílias de crianças com doença crônica e as modificações na rotina da família foi construída nesse processo e apontou a diversidade da composição da rede social, evidenciando que o apoio social fornecido pela rede é significativo, porém nem sempre é contínuo e condizente com as necessidades das famílias.

Descritores: Apoio Social; Doença Crônica; Família; Criança; Enfermagem.

\begin{abstract}
Chronic disease in childhood affects the family social relations. The social network can contribute for a better coping by giving support. This work aims to analyze the fragilities of the social network of families in this condition. It is a qualitative study conducted in a public hospital of Paraíba, from April to June 2011, using genogram, ecomap and semi-structured interview with seven family members of children with chronic disease. The thematic analysis of the results helped to characterize the network and understand the social interactions in the course of the disease and the types of support received. The empirical category (dis)articulation of the social network and the modifications in family routine was built in this process and pointed the diversity of the social network composition, emphasizing that the social support provided by the network is significant, however, not always continuous and suitable with the needs of the families.
\end{abstract}

Key words: Social Support; Chronic Disease; Family; Child; Nursing.

\section{RESUMEN}

La enfermedad crónica en la niñez afecta las relaciones sociales familiares. La red social podrá contribuir para un mejor enfrentamiento cuando ofrece apoyo. Se objetivó analizar las fragilidades de la red social de familias de niños con enfermedad crónica. Se trata de una investigación cualitativa, realizada en un hospital público de Paraíba, en el período de abril a junio de 2011, utilizando genograma, ecomapa y entrevista semiestructurada con siete familiares de niños con enfermedades crónicas. El análisis temático de los resultados posibilitó caracterizar la red y aprehender las interacciones sociales en la trayectoria de la enfermedad y los tipos de apoyo que recibieron. La categoría empírica (des)articulación de dicha red y las modificaciones en la rutina de la familia, fue construida en ese proceso y apuntó la diversidad de la composición de dicha red, evidenciando que el apoyo social fornecido por la red supradicha es significativo, sin embargo, no siempre es continuo y condicente con las necesidades de las familias.

Palabras clave: Apoyo Social; Familia; Enfermedad Crónica; Niño; Enfermería.

\section{AUTOR CORRESPONDENTE Yana Balduíno Araújo E-mail: yanabalduino@yahoo.com.br}




\section{INTRODUÇÃO}

A Organização Mundial da Saúde conceitua doença crônica como aquela que normalmente possui desenvolvimento lento, dura períodos extensos e têm efeitos de longo prazo, difíceis de prever. A maioria não tem cura, entretanto, várias delas podem ser prevenidas ou controladas por meio da detecção precoce e terapêutica adequada ${ }^{(1)}$.

Quando uma criança e sua família vivenciam a doença crônica, têm seu cotidiano modificado devido à interrupção das atividades diárias, internações prolongadas, realização de exames, adesão à terapêutica, efeitos indesejáveis advindos da própria medicação, limitações na compreensão do diagnóstico, desajuste financeiro, angústia, sofrimento, dor e medo constante da possibilidade de morte ${ }^{(2-3)}$. Porém, a depender da condução no processo diagnóstico e de tratamento de cada tipo de doença crônica, pode haver melhora na qualidade de vida dessas crianças.

O funcionamento familiar sob condições incomuns de tensão, como ocorre por ocasião do diagnóstico de uma doença crônica em um de seus membros, leva à desorganização, pois o comportamento de cada um precisa ser readaptado em função das demandas decorrentes da doença, como também das expectativas de um indivíduo em relação a outro ${ }^{(4)}$.

$\mathrm{Na}$ adaptação às modificações decorrentes da doença crônica, são necessárias estratégias para o enfrentamento, as quais dependem da complexidade da doença, da demanda de cuidados, da fase em que a doença se encontra, como também do suporte e do apoio das redes sociais nas quais a criança e sua família estão inseridas ${ }^{(5)}$.

A rede social é a estrutura pessoal ou grupal por meio da qual o apoio social, aspecto funcional das relações dessa rede, pode fluir. O apoio social influencia no bem-estar emocional, associa-se à redução da mortalidade, à prevenção de doenças e à recuperação da saúde, embora os mecanismos que levam a isso não sejam totalmente explicados ${ }^{(6)}$. No Brasil, o aspecto funcional do apoio social compreende cinco tipos ${ }^{(7)}$ :

1. Apoio material: provisão de recursos e de ajuda material, como dinheiro ou empréstimo de utensílios, em caso de necessidade emergencial;

2. Apoio afetivo: demonstrações físicas de amor e de afeto;

3. Apoio emocional: compreensão, confiança, estima, escuta e interesse;

4. Apoio de informação: disponibilidade de pessoas para a obtenção de conselhos, de informações ou de orientações;

5. Interação social positiva: disponibilidade de pessoas com quem se divertir e relaxar.

Envolve ainda as dimensões de disponibilidade e satisfação, ou seja, o quantitativo de pessoas integrantes da rede a quem o indivíduo pode recorrer e o nível de satisfação em relação ao apoio disponível(8). Essas duas dimensões são essenciais para qualificar a percepção de apoio social e variam entre indivíduos da mesma rede. Assim, para uns o apoio social só será percebido como positivo quando muitas pessoas estiverem disponíveis para fornece-lo, enquanto que, para outros, uma só pessoa é suficiente para satisfazer todas suas demandas de apoio.

Uma terceira dimensão, a reciprocidade, também faz parte desse processo ${ }^{(9)}$, pois o apoio implica necessariamente troca, na qual são beneficiados tanto quem o dá quanto quem o recebe. Assim, para que o apoio social seja recíproco, precisa ir ao encontro das necessidades de cada indivíduo, que irá percebê-lo como satisfatório e sentir-se-á importante em sua rede.

A rede social das famílias de crianças com doença crônica pode ser considerada uma estratégia para melhorar sua qualidade de vida, tanto no início, quanto no curso da doença. Contudo, apesar do aumento significativo de pesquisas sobre rede social nas últimas décadas, pouco se sabe sobre a rede de famílias de crianças com doença crônica, tendo em vista que uma das principais características da doença crônica é o cuidado contínuo.

Frente ao pressuposto de que uma rede social fortalecida poderá contribuir para o enfrentamento da condição crônica, este estudo buscou responder o seguinte questionamento: Como se articula a rede social de famílias de crianças com doença crônica? Nesse sentido, seu objetivo foi analisar as fragilidades da rede social de famílias de crianças com doença crônica.

\section{MÉTODO}

Pesquisa qualitativa, realizada em um hospital público da Paraíba, no período de abril a junho de 2011. O foco do estudo foi o indivíduo como parte de um subgrupo familiar, no qual tanto indivíduos como relacionamentos são estudados, tendo a família como contexto ${ }^{(10)}$. Sete mães foram selecionadas como representantes das famílias das crianças, por atenderem os critérios de inclusão: cuidar da criança no domicílio e acompanhá-la no hospital.

Para a coleta dos dados foram utilizados inicialmente o genograma e o ecomapa, técnicas que permitem a leitura rápida e abrangente da organização familiar e a avaliação dos recursos familiares atuais ou em determinado contexto vivido pela família $^{(11)}$. Para o aprofundamento dos aspectos identificados durante a construção do genograma e ecomapa, utilizou-se como técnica complementar a entrevista semiestruturada em profundidade norteada pela questão: Que pessoas fazem parte de sua rede social e qual o apoio foi recebido para o enfrentamento da doença crônica do(a) seu(sua) filho(a)?

As entrevistas tiveram duração de 40 a 60 minutos, foram gravadas em MP3, transcritas na íntegra e seu conteúdo submetido à análise temática ${ }^{(12)}$, desenvolvida em três etapas: pré-análise, exploração do material e tratamento, inferência e interpretação dos dados. A etapa da pré-análise corresponde à organização das ideias propriamente ditas, de forma sistemática. Tal processo foi otimizado pela organização do material disponível para a análise. Assim, as entrevistas foram transcritas na íntegra e realizou-se sua leitura flutuante. Na etapa de exploração do material, foram destacadas as unidades de registro e a temática em relevo, tendo em vista a recorrência dos dados empíricos. Esse processo permitiu eleger as unidades temáticas contidas no conjunto dos discursos, em um movimento de classificação. Posteriormente, foi construída a unidade 
temática central, cujo desmembramento permitiu a identificação de temas que foram agregados em duas categorias empíricas: (Des)articulação da rede social de famílias de crianças com doença crônica; e Modificações na rotina da família.

Os resultados obtidos permitiram que fossem feitas inferências e interpretações à luz da fundamentação teórica que norteou o estudo. Para garantir a privacidade e o sigilo das informações, os dados referentes a cada família foram representados pela letra $F$, correspondente a família, seguida por uma letra do alfabeto, conforme ordem de realização das entrevistas. Assim, o primeiro familiar a participar do estudo teve sua família representada pelas letras " $F$ " e " $A$ " e todos os nomes fictícios dos demais familiares foram escritos com a inicial " $\mathrm{A}$ ", e assim sucessivamente, até a Família G.

As famílias que participaram do estudo possuíam crianças com os seguintes diagnósticos: insuficiência cardíaca (FA), fibrose cística (FB e FG), síndrome nefrótica (FC e FF), anemia aplástica (FD) e síndrome de Edwards (FE). Passavam pelos momentos de diagnóstico, adesão à terapêutica (Famílias FA, FB, FD e FG) e recidivas (Famílias FC, FE e FF).

O estudo foi aprovado pelo Comitê de Ética em Pesquisa do hospital sob protocolo 082/2011 e todos os sujeitos assinaram o Termo de Consentimento Livre e Esclarecido.

\section{RESULTADOS E DISCUSSÃO}

\section{(Des)articulação da rede social de famílias de crianças com doença crônica}

Diante de um problema de saúde, a família aciona mecanismos próprios de enfrentamento com os meios construídos em sua trajetória, com variações na oferta e na disponibilidade de recursos. A experiência em cuidar da criança, relacionada a reconhecer seu crescimento e desenvolvimento saudável, capacita os familiares a perceber o aparecimento de uma doença. Geralmente é identificada pela mãe, que consegue interpretar e responder de forma adequada às necessidades do filho, por mais sutis que sejam. Contudo, quando as competências da família esgotam-se e os pais percebem que não conseguem resolver tal problema de saúde no domicílio, há uma mobilização em busca dos serviços de saúde ou pessoas da rede social.

Os serviços de saúde, principalmente na atenção hospitalar, aparecem no depoimento dos familiares como um dos primeiros locais acionados para que a doença seja desvendada, explicada e tratada. Os pais acreditam que os filhos estariam mais bem amparados no hospital do que na rede básica, por isso, preferem ir diretamente ao hospital a fim de sanar problemas que poderiam ser resolvidos na Atenção Básica ${ }^{(13)}$. A dificuldade de acesso neste nível de atenção, devido ao número limitado de atendimentos diários, torna-se uma das justificativas utilizadas pelas famílias para buscar diretamente o hospital. Contudo, o hospital não se configura como acesso de primeiro contato na concepção da Atenção Primária à Saúde e rede de atenção do Sistema Único de Saúde.

A família busca atendimento na Atenção Básica quando reside em cidades do interior e de pequeno porte, que não possuem hospital. Entretanto, em alguns casos, o modo de organização do serviço não contribui para que o problema de saúde seja resolvido ou encaminhado a outro nível de atenção. Além disso, as famílias sentem-se pouco acolhidas. Esses fatores influenciam diretamente a rede social e a percepção de apoio social recebido pelas famílias, conforme evidenciam os relatos:

Ela era sempre magrinha e pequena, e foi minha mãe e minhas irmãs que viram a diferença [...] quando eu a vi já estava inchadinha, e aí eu vim direto para cá (hospital-escola). Não fui nem no posto de saúde, não (FC).

As manchas que saíram eram bem roxas e grandes [...]. Fui ao posto, mas o médico disse que não sabia o que significavam aquelas manchas. Perguntou se ela tinha levado alguma pancada, passou um remedinho, ela tomou, mas não serviu de nada. Depois de uma semana voltei para o posto e disse: Olha, a menina aqui está vomitando e está desse jeito. Ele (médico) foi só fazendo os papéis e encaminhando [...]. Não era pancada, era anemia muito forte, até as plaquetas dela estavam muito baixas, estava em 5000 mil. Quando eu cheguei no hospital a doutora disse logo: Mãe, por que a senhora deixou isso acontecer? Eu disse que eu não sabia de nada e nunca tinha nem visto essas coisas. Depois a médica encaminhou para cá (hospital-escola) (FD).

A busca pelo atendimento nos serviços citados nos depoimentos torna-se ainda mais frustrante e difícil quando os profissionais de saúde envolvidos na rede social não reconhecem as demandas de apoio da família. Por outro lado, os profissionais que têm conhecimento dessa necessidade fornecem o apoio informativo de forma equivocada, comprometendo o entendimento da condição de saúde da criança e prejudicando o enfrentamento da doença.

As experiências narradas indicam principalmente falta de comunicação entre os serviços de saúde, descaso na oferta de cuidado adequado à criança e à família, longa espera pela definição do diagnóstico, ausência ou inadequação do apoio informacional e emocional dos profissionais de saúde. Este apoio é fundamental para que a família possa amenizar a tensão e a ansiedade frente ao desconhecido, pois a espera pelo diagnóstico pode demorar anos.

Os dados deste estudo confirmam os achados de uma pesquisa $^{(14)}$ que atribui à fragilização dos serviços de atenção básica a falta de acolhimento, pois a escuta qualificada está comprometida e não há interesse pela demanda do outro. Nesse processo identifica-se o enfraquecimento do vínculo e da responsabilização, inviabilizando a produção do cuidado pautado na dimensão dialógica do encontro entre profissionais e famílias de crianças com doença crônica, restringindo a rede social que já se mostra desarticulada.

Tanto na Atenção Básica quanto na hospitalar há fragmentação das ações de cuidado, na medida em que não há compartilhamento de informações sobre essas crianças e os serviços não estão articulados em redes de atenção à saúde. As famílias trilham uma caminhada tortuosa e desgastante até 
encontrar um serviço ou um profissional disposto a fornecer uma informação sobre onde e a quem recorrer. Esse fato é evidenciado na Família B que desde os primeiros sinais e sintomas da doença procurava assistência nos serviços de saúde, mas nenhum profissional encaminhou a criança para um especialista e nem orientou a família sobre a necessidade de cuidados e exames específicos.

Dentre as formas apoio social para as famílias estão a articulação em rede dos serviços de média e alta complexidade, para garantir que o diagnóstico da doença e o tratamento específico possam ser agilizados, e a continuidade do cuidado em saúde na perspectiva de co-responsabilidade na rede social, ou seja, entre os serviços de saúde, os profissionais, a família e a coletividade.

Eu queria que ela (médica da ESF) tivesse encaminhado antes, tivesse cuidado dele logo quando ele era novinho, com um ano de vida, quando ele começou com isso. Eu queria ter recebido essa informação antes, ele já estaria adiantando o tratamento. Mas na última consulta que eu fui com ele, a médica nova disse assim: 'Mãe, eu não sei mais o que fazer, a única coisa que posso fazer é encaminhar para o pneumologista. Lá ele (referindo-se ao pneumologista) vai descobrir tudo o que ele (a criança) tem'. Aí eu disse: 'Meu Deus! Meu sonho é ir para esse médico!' Da última vez que ele ficou internado, a médica do AM (hospital pediátrico estadual) disse que ele tinha que ir para esse médico (pneumologista), mas não me deu encaminhamento $(F B)$.

Algumas doenças crônicas demandam um tempo maior para a definição do diagnóstico e, em determinados casos, essa demora pode implicar, diminuição da sobrevida da criança, além de provocar na família sentimentos de ansiedade e impotência, sendo necessário seu acompanhamento e apoio pela rede social. Doenças como fibrose cística, que deveriam ser diagnosticadas com maior agilidade e brevidade a fim de garantir qualidade de vida à criança, não têm tido essa resolutividade devido à organização incipiente da rede de serviços de atenção à saúde.

Há casos em que a criança e seu acompanhante passam longos períodos hospitalizados à espera do diagnóstico da doença e muitas vezes voltam para casa sem respostas, levando consigo o medo da morte e incertezas sobre o futuro da criança. Quando isso acontece, as famílias buscam outros serviços de saúde que possam resolver seu problema.

Quando os serviços de saúde focam o cuidado no usuário e sua família, viabiliza-se a construção de espaços de escuta qualificada. O reconhecimento de 'não saber sobre a doença da criança' não significa deixar de escutar a família e dar espaço para que esta compartilhe sentimentos, demandas e anseios. Esse modo de organização do processo de trabalho permite o estabelecimento de vínculos e corresponsabilização, contribuindo para que a família se sinta acolhida.

No AM (hospital pediátrico estadual) foi péssimo porque ela passou um mês inteiro sendo furada e ninguém descobriu o que ela tinha, eu não sabia nada da doença e se eu perguntasse a causa da doença os médicos diziam: Não sei explicar. Aí quando ela estava em casa, levei-a para outro hospital, e lá tinha uma plantonista trabalhando que era daqui do HU (hospital-escola). Essa médica me disse que aqui em João Pessoa, eu só encontrava tratamento para ela aqui. Aí pronto, foi Jesus quem botou ela na vida da gente (FF).

Da primeira vez, o médico do posto poderia ter feito mais [...] encaminhado logo ela e ter pedido exames. E da segunda vez foi bom, ele encaminhou logo. Eles fizeram o melhor que puderam. Porque só passando remédio, passando remédio, sem descobrir nada do que era não estava pior? (FD).

Famílias que não conseguem ter acesso aos serviços ou que são atendidas sem resolutividade estão tendo seus direitos violados, se considerarmos as normativas do Ministério da Saúde que preconiza a garantia da manutenção da Atenção Básica em Saúde como a porta de entrada do sistema de saúde, de fácil acesso, disponível e resolutiva para o atendimento às necessidades de saúde da população ${ }^{(15)}$. Tal violação compromete a assistência adequada e posterga sua ocorrência, afetando negativamente o diagnóstico e o prognóstico da criança, bem como o manejo do problema, com consequente busca por serviços de saúde em outro nível de atenção.

\section{Modificações na rotina da família}

Os serviços de saúde têm contribuído para estabelecer e fortalecer os vínculos com essas famílias, que desde o início da doença da criança começam a sofrer e enfrentar mudanças imprevisíveis em sua rotina ${ }^{(16)}$, tornando ainda mais doloroso conviver com a doença. Essas mudanças abrangem a forma de organização familiar para o cuidado da criança doente e as reações dos irmãos saudáveis em relação à doença.

A reconfiguração de papéis nem sempre é dialogada no seio da família, mas imposta ${ }^{(17)}$, ou seja, a mãe que antes já assumia o cuidado dos filhos, continua com essa atribuição a partir da definição do diagnóstico de doença crônica. Essa centralidade da responsabilidade pelo cuidado em um dos membros pode até mesmo levar à desintegração familiar, pois a mãe precisa se dedicar às muitas necessidades da criança doente o que a leva a se ausentar do lar por um tempo indeterminado. Embora sobrecarregada, a mãe ainda precisa lidar com as diversas reações dos outros membros da família, tais como dificuldades na aceitação e falta de compartilhamento dos cuidados à criança doença.

A (pai da criança) não cuida dos meninos e agora está com dificuldade para cuidar de A. Ele tem o sábado e o domingo para cuidar e não cuida, prefere ir jogar bola e beber. Aí, quando precisa, fica com dificuldade para cuidar dela (FA).

O pai de C. nunca foi um pai presente, nunca deu nada a C., e às vezes quando eu ia lá deixar ela, por duas vezes e ele veio com queixa dizendo que não tinha ninguém para ajudar e não podia ficar com ela (FC). 
Quem cuida dele sou eu. Eu me preocupo muito, principalmente quando ele está doente, tossindo muito, de noite ele não dorme [...]. Às vezes o pai também se preocupa muito, mas eu que fico lá acordada com ele. Sempre o pai é diferente da mãe, o pai se preocupa também, mas é diferente $(F B)$.

Apesar das atribuições da mãe como cuidadora dos filhos, é fundamental que o pai também contribua e que ambos possam construir um plano de responsabilização conjunta pela manutenção dos cuidados à criança, constituindo uma fonte de apoio social importantíssima e fundamental para a família nuclear.

Nos depoimentos acima, identifica-se que o genitor permanece à margem dessa responsabilização, mantendo uma postura de distanciamento dos cuidados com a criança, e continua desenvolvendo suas atividades cotidianas, abrindo espaço para interpretação de que a doença crônica do filho pouco modificou suas atribuições e rotina. Tal posicionamento pode afetar o enfrentamento de toda a família, especialmente da mãe, que vivencia os efeitos da sobrecarga do cuidado à criança e ainda precisa assumir grande parte das tarefas domésticas e dos cuidados com os filhos saudáveis.

Estudo $^{(18)}$ enfatiza que a mãe assume sozinha os cuidados por perceber facilmente a indisponibilidade da própria família em fornecer apoio social. Aceita essa incumbência passivamente porque considera que a responsabilidade de cuidar é exclusivamente sua. A centralização na figura materna é uma das consequências, já que a mãe acredita que não há outro familiar disponível para realizar o cuidado e que ninguém cuida tão bem quanto ela. Desse modo, toma para si o que poderia ser compartilhado com todos os membros da família. A falta de apoio para essas mães pode acarretar em esgotamento físico e mental ${ }^{(19)}$ e, além de trazer prejuízos para sua saúde, pode repercutir na qualidade do cuidado prestado à criança.

Cabe à equipe de saúde dialogar com a mãe acerca da elaboração de estratégias que envolvam toda família na discussão sobre a importância de dividir responsabilidades, estimular o revezamento no cuidado da criança, diminuindo assim a sobrecarga da cuidadora principal. Além disso, é importante sensibilizá-la para que reconheça a necessidade e esteja aberta para aceitar o apoio da família, dos amigos e vizinhos, para o compartilhamento dessa tarefa.

A tristeza e a culpa também são sentimentos comuns às mães, pois precisam deixar os outros filhos sob os cuidados de algum integrante da rede, geralmente as avós, enquanto permanecem no hospital com a criança doente por muitos dias. Ainda que contem com o apoio instrumental da rede, é preciso encontrar alternativas para a diminuição desses sentimentos, que reforçam na mãe a centralização do cuidado e a despersonalização resultante da dedicação exclusiva à criança, oprimindo-se e esquecendo-se de sua própria vida.

É difícil para mim, porque deixo meus outros filhos com minha mãe (FG). Estou agoniada, sem fazer nada, você já viu alguém que precisa fazer suas coisas e não pode fazer, não ficar agoniada? Desde que descobriu a doença ela está aqui, já faz dois meses (FD).
A rede social dessas famílias deve estimular o compartiIhamento de responsabilidades e dar suporte para que a mãe sinta-se segura e capaz para cuidar da criança e de si e, mesmo estando distante do lar, confie que a sua família está sendo bem assistida. Os profissionais de saúde podem cooperar envolvendo toda a família no plano de cuidados à criança, ajudando-a a desconstruir a centralidade.

Uma das maneiras de contribuir para que essas mulheres cuidadoras sintam-se menos cobradas diante da responsabilidade de assumir sozinhas o cuidado da criança enferma é desvestir o discurso da ideologia dominante que reforça a opressão e dificulta o empoderamento. Esse discurso também causa alienação dos cuidadores, alimentando a cultura do silêncio e da aceitação passiva, reforçando o papel da boa mãe, excluindo o restante da família do processo de cuidar da criança em um processo de responsabilização e culpabilização da mãe-mulher-cuidadora ${ }^{(19)}$.

Os irmãos saudáveis também precisam ser assistidos, uma vez que podem reagir negativamente à doença ou ao irmão(a) doente. No presente estudo, o representante da família citou os filhos saudáveis como aliados no processo de cuidar do irmão doente, acreditando na cura da doença e compreendendo as diferenças no cuidado dos pais.

E. alimenta e cuida muito bem dele, se eu precisar sair, ela fica com ele, se ele precisar tomar medicação eu escrevo tudo no papel e ela dá, dá a dieta dele direitinho, confio deixar mais com ela do que com minha mãe porque $E$. cuida melhor dele. Ela sabe mais do que minha mãe (FE).

Diante da doença, alguns irmãos, geralmente os mais veIhos, apresentam-se mais maduros, com responsabilidade, independência, e passam a demonstrar maior simpatia por outras pessoas. O desejo de proteger e cuidar do irmão doente inclusive os leva a compreender os sentimentos da mãe ${ }^{(8)}$. Embora devam apoiar essas reações positivas à doença, os familiares precisam entender que delegar aos outros filhos a responsabilidade de executar cuidados complexos, como a alimentação e administração de medicamento por sondas, pode não ser prudente e representa riscos para vida da criança doente, já que até mesmo as mães possuem dificuldades em desenvolver tais habilidades. As mães de crianças com necessidades especiais de saúde realizam esse tipo de cuidado com base em saberes e práticas que não pertencem ao seu cotidiano existencial e tal cuidado é totalmente dependente de acertos e erros para garantir ou não a sobrevivência da criança ${ }^{(19)}$.

Eles são unidos. Ele defende e não deixa ela comer certas coisas, quando tem festa na igreja e ela quer comer ele diz:' F., tu não pode comer! Às vezes ela fala o que ele pode e ela não pode, ai eu digo, que ela tem problema (referindo-se a doença) e é gordinha, ele é homem pode comer mais. Ela acaba se conformando, todo mundo explica, tanto a parte da minha família como a de meu marido ajuda (FF).

D. (filha) é quem mais me ajuda. Ela quem trouxe a D., e a outra (referindo-se a outra D.) é quem vem ficar aqui 
(hospital-escola). Ela vem e passa três, quatro dias e vai embora, e eu me sinto bem [...] o direito (referindo-se ao dever) do filho é ajudar a mãe e o pai. E eu só conto com minha família mesmo, não peço nada a ninguém, não (FD).

A família também precisa saber como dar explicações para a criança doente sobre sua condição de saúde e implicações desta para sua vida, para que ela possa compreendê-las sem se sentir estigmatizada e diferente dos irmãos saudáveis e das outras crianças de sua faixa etária. $\mathrm{O}$ apoio informacional que a criança deve receber precisa condizer com as suas necessidades, cognição e idade. Contudo, até que ponto a família tem recebido orientações para fazê-lo, se a maioria nem conhece a doença do filho?

Há situações em que a possibilidade de cura está na própria família, a exemplo da Família D: D’ possui anemia aplástica, um tipo de anemia rara e potencialmente fatal, que pode ser curada com transplante de medula óssea. Nessa família, três irmãos são doadores compatíveis com a criança e a esperança da cura é o que tem movido toda a família a enfrentar a doença e o longo período de hospitalização que a criança e sua mãe vêm passando.

Por isso que ter muito filho é bom e é ruim. Ruim porque nenhum ajuda [...] eles não têm trabalho [...] e é bom porque, três irmãos são compatíveis com ela. E se eu não tivesse muito filho? la esperar por algum que pudesse doar. A melhor parte foi essa. Eu me senti no céu (FD).

Alguns irmãos saudáveis percebem a doença do irmão como algo que causa a separação entre os familiares, causando-lhes instabilidade emocional e medo(20). Intervenções que previnam ou minimizem esses efeitos precisam ser elaboradas juntamente com a família, que apontará as demandas de apoio. De acordo com as demandas apresentadas, os integrantes da rede social, entre eles os profissionais de saúde, poderão prover esse auxílio, atendendo às necessidades dos irmãos e estimulando toda a rede para que possa estar articulada, fortalecida e apta para ofertar o apoio social.

B. não tem preconceito com nada dele. Às vezes ela fala que, quando eles estão arengando, ela diz que eu vou reclamar com ela, aí ela diz: 'Eu sei, eu sei mãinha, que a senhora dá mais atenção à ele, eu sei que a senhora gosta mais dele mesmo'. Veja bem, eu não gosto mais dele, não! É igual os dois! Mas ela (referindo-se à B.), na hora da confusão em casa, percebe que eu gosto mais dele. [...]. Eu não sei se ela fala isso porque nota alguma coisa diferente, acho que eu também dou mais atenção a ele na hora da precisão, e ela tem saúde. Ele não precisa de mais atenção, mais cuidado. Talvez seja isso que ela perceba e diga que é diferente (FB).

O profissional de saúde integra a rede social e pode realizar a articulação com outros serviços e níveis de atenção à saúde e intermediar conflitos entre os membros da família, a fim de integrá-la e possibilitar melhor aporte de cuidados.

No intuito de viabilizar o cuidado relacionado às restrições alimentares da criança doente, as mães desenvolvem estratégias a partir do que lhe é recomendado, e aplicam para os demais filhos que são saudáveis. Essa atitude nem sempre é recomendada, tendo em vista que o irmão saudável poderá reagir com revolta e chantagem emocional, por se sentir ameaçado em sua individualidade e preferências alimentares para se adaptar à nova dieta imposta pela doença, dificultando ainda mais a aceitação do irmão doente e sua condição. Ressalta-se com isso a necessidade premente de estimular essas crianças para participar e contribuir para o cuidado, sem perder sua individualidade.

A comida é diferente, mas do jeito que eu faço para $C$., faço para C'e C", sempre sem sal. Eu já me acostumei, mas do jeito que eu cuido de uma, eu cuido da outra [...]. Tem só algumas comidas que C. não pode comer, aí eu até nem compro para ela não ficar chateada, brigando com as irmãs por conta disso. Às vezes eu compro e escondo e dou só para as duas menores [...] C' fica dizendo: Olha, eu tenho e nem te dou. Fica debochando, aí C. está perto e elas brigam por conta de comida (FC).

Enquanto as práticas educativas estiverem pautadas na negação das condições da doença, a família sentirá dificuldades para lidar com situações corriqueiras, como a referida pela Família C. O que se propõem é que possam se adaptar às restrições da doença e encontrar alternativas para viver em equilíbrio, sem, contudo, negar suas repercussões. Para que essa adaptação ocorra com menos sofrimento, a rede social precisa estar presente e atenta às demandas que surgirão, fornecendo o apoio social satisfatório do ponto de vista da família.

A constante (des)organização da dinâmica familiar devido à doença crônica deve ser considerada como demanda, e é importante que a rede social apoie a família para a co-responsabilização dos envolvidos, encorajando o revezamento dessas pessoas no cuidado à criança, a fim de estimular a aceitação da doença por parte dos irmãos saudáveis, delegando pequenas responsabilidades no cuidado com o irmão doente, além de envolver a família em grupos colaborativos que desenvolvam atividades de educação em saúde que os orientem quanto aos aspectos que envolvem a doença, o tratamento e os cuidados.

Nesses grupos é imprescindível que o conhecimento da família seja respeitado e que não haja imposições de saberes, mas o estabelecimento de uma relação horizontalizada, no mesmo plano de importância e valorização dos conhecimentos do profissional de saúde e da família. Quando colocados no mesmo plano, esses saberes complementam-se, possibilitando a produção de um cuidado mais rico e ampliado.

\section{CONCLUSÕES}

Considerando que a definição do diagnóstico da enfermidade desencadeia modificações na rotina das famílias e no comportamento de seus membros, principalmente dos irmãos saudáveis e do cuidador principal da criança (a mãe), enfatiza-se a relevância do apoio social e o fortalecimento da rede para o enfrentamento da doença. 
No início da trajetória dessas famílias em busca de atendimento nos serviços de saúde percebeu-se que não houve acolhimento, tampouco, a formação de vínculo entre família/profissionais. A comunicação também não foi efetiva para permitir que a família obtivesse conhecimento sobre o que estava acontecendo e o que estava por vir. O primeiro encontro da família com o serviço de saúde é fundamental e pode ser decisivo tanto para o profissional de saúde, que deveria estar disposto a entender, ajudar e estar presente como parceiro nessa trajetória, como para a família, que pode vir a encontrar um forte aliado no enfrentamento da doença.

Cabe aos profissionais e gestores de saúde adequar a oferta de serviços às necessidades da família, a fim de oferecer o apoio necessário para suas demandas. Esse foco na produção do cuidado permite ir além do atendimento das necessidades de saúde, ampliando-se em direção à conquista da confiança mútua, pautada na busca efetiva do sucesso terapêutico almejado.
A rede social das famílias que enfrentam a doença crônica da criança é composta por diferentes pessoas e instituições, e o apoio social fornecido por essa rede é significativo, porém nem sempre é contínuo e condizente com as necessidades das famílias. É necessário que haja o fortalecimento e o comprometimento dos integrantes da rede para que o apoio ofertado à família seja adequado a suas demandas, contínuo no processo vivencial dessa experiência e provedor de suporte social capaz de encorajar o enfrentamento das adversidades que surgem no processo de enfrentamento da condição crônica da criança.

A construção da rede social desde o início da trajetória e sua manutenção em toda a caminhada com a doença crônica vivenciada pela família é diretamente influenciada pelo vínculo estabelecido nas relações em cada encontro de cuidado. Portanto, formas de estreitar esses vínculos precisam ser elaboradas, para despertar o espírito de solidariedade e colaboração entre os integrantes dessa rede.

\section{REFERÊNCIAS}

1. Organização Mundial da Saúde [homepage na internet]. Prevenção de doenças crônicas: um investimento vital. [acesso em 06 de Set 2011]. Disponível em: http://www.who.int/ chp/chronic_disease_report/contents/en/index.html >

2. Amador DD, Gomes IP, Coutinho SED, Costa TNA, Collet N. Concepção dos enfermeiros acerca da capacitação no cuidado à criança com câncer. Texto \& Contexto Enferm. 2011;20(1):94-101.

3. Nascimento LC, Rocha SMM, Hayes VE, Lima RAG. Crianças com câncer e suas famílias. Rev Esc Enferm USP. 2005;39(4):469-74.

4. Mendes AMC, Bousso RS. Não podendo viver como antes: a dinâmica familiar na experiência do transplante hepática da criança. Rev Latino-Am Enferm. 2009;17(1):11-7.

5. Vieira, MA, Lima, RAG. Crianças e adolescentes com doença crônica: convivendo com mudanças. Rev Latino-Am Enferm. 2002;10(4):552-60.

6. Caixeta CRCB, Morraye MA, Villela WV, Rocha SMM. Social support for people living with AIDS. Rev Enferm UFPE. [periódico na internet]. 2011 [acesso em $12 \mathrm{dez}$ 12];5(8):1-10. Disponível em: http://www.ufpe.br/revistaenfermagem/index.php/revista/article/view/1866.

7. Griep RH, Chor D, Faerstein E, Werneck GL, Lopes CS. Confiabilidade e validade de instrumentos de medida de rede social e de apoio social utilizados no Estudo Pró-Saúde. Cad Saúde Pública. 2005;21(3):703-14.

8. Simioni AS, Geib LTC. Percepção materna quanto ao apoio social recebido no cuidado às crianças prematuras no domicílio. Rev Bras Enferm. 2008;61(5):645-51.

9. Gonçalves TR, Pawlowski J, Bandeira DR, Piccinini CA. Avaliação de apoio social em estudos brasileiros: aspectos conceituais e instrumentos. Ciênc Saúde Coletiva. 2011;16(3):1755-69.

10. Robinson CA. Unifying distinctions for nursing research with persons and families. J Fam Nurs. 1995;1(1):8-29.
11. Agostinho M. Ecomapa. Rev Port Clíni Geral. 2007;(23): 327-30.

12. Minayo MCS. O desafio do conhecimento: pesquisa qualitativa. 12. ed. São Paulo: Hucitec-Abrasco; 2010.

13. Batistela S, Guerreiro NP, Rossetto EG. Os motivos de procura pelo pronto socorro pediátrico de um hospital universitário referidos pelos pais ou responsáveis. Semina Cienc Biol Saúde. 2008;29(2):121-30.

14. Nobrega VM, Collet N, Silva KL, Coutinho SED. Rede e apoio social das famílias de crianças em condição crônica. Rev Eletrônica Enferm. [periódico na internet]. 2010 [acesso em 22 ago 2011]; 12(3):431-40. Disponível em: http://www.fen.ufg.br/revista/v12/n3/v12n3a03.htm.

15. Shimizu HE, Rosales C. As práticas desenvolvidas no Programa Saúde da Família contribuem para transformar o modelo de atenção à saúde? Rev Bras Enferm. 2009;62(3):424-9.

16. Gudmundsdóttir HS, Elklit A, Gudmundsdóttir DB. PTSD and psychological distress in Icelandic parents of chronically ill children: does social support have an effect on parental distress?. Scand J Psychol. 2006;47(4):303-12.

17. Rossato LM, Angelo M, Silva CAA. Cuidando para a criança crescer apesar da dor: a experiência da família. Rev Latino-Am Enferm. 2007;15(4):1-8.

18. Beck ARM, Lopes MHBM. Cuidadores de crianças com câncer: aspectos da vida afetados pela atividade de cuidador. Rev Bras Enferm. 2007;60(6):670-5.

19. Neves ET, Cabral IE. Cuidar de crianças com necessidade especiais de saúde: desafios para as famílias e enfermagem pediátrica. Rev Eletrônica Enferm. [periódico na internet]. 2009 [acesso em 30 out 2011]; 11(3):527-38. Disponível em:http://www.fen.ufg.br/revista/v11/n3/v11n3a09.htm

20. Pedro ICS, Galvão CM, Rocha SMM, Nascimento LC. Apoio social e famílias de crianças com câncer: revisão integrativa. Rev Latino-Am Enferm. 2008;16(3):477-83. 